\title{
The Model of Network Consulting Communication at the Early Stages of Entrepreneurship
}

\author{
IRINA GONTAREVA \\ Dr. Sci. in Economics \\ Professor \\ Department of Marketing, Management \\ and Entrepreneurship \\ V. N. Karazin Kharkiv National University \\ 4 Svobody Sq., Kharkiv, 61022 \\ UKRAINE \\ VITALINA BABENKO \\ Dr. Sci. in Economics \\ Professor
}

Department of International E-Commerce and Hotel\&Restaurant Business

V.N. Karazin Kharkiv National University

Svobody Sq., 4, Kharkiv, 61022

UKRAINE

\author{
NATALIIA SHMATKO \\ Dr. Sci. in Economics \\ Associate Professor \\ Department of Management Innovative Entrepreneurship and International Economic Relations \\ National Technical University «Kharkiv Polytechnic Institute» \\ 2, Kyrpychova str., Kharkiv, 61022 \\ UKRAINE
}

\author{
OLEKSANDR LITVINOV \\ Dr. Sci. in Economics \\ Associated professor \\ Department of Economics of Enterprise and Business Organization \\ Odesa National Economic University \\ 8 Preobarazhenskaya str., Odesa, 65082 \\ UKRAINE
}

\section{OBRUCH HANNA}

Candidate of Economic Sciences

Senior Lecturer

Department of Economics and Management of Industrial and Commercial Business

Ukrainian State University of Railway Transport

Feuerbach Square 7, 61050, Kharkiv

UKRAINE 
Abstract: - The essence of the early stages of entrepreneurial activity is a gradual refinement and transformation of the cognitive model of a business project into an ongoing organizational structure.

The aim of the article is forming the structure of a model of consulting communication of prospective and novice entrepreneurs based on an open multilateral platform. The methodological basis of the study is the cognitive approach to organization of network communication.

The conceptual structure of the organization model of the communication process, based on the principles of adaptive (transactional) feedback, is presented. The result of consulting communication is transformation of an initial business idea, resting upon the personified implicit knowledge of the entrepreneur, into an informationbased business model of the startup's activities. The transformation is carried out in the process of interaction with specialists who play the role of an expert, evaluator, or mentor and have proven semantic and pragmatic ideas about the essence of entrepreneurial activity. Organizational functions are performed by the platform administrator, who owns the techniques for conducting complex multilateral communication.

The proposed conceptual model of network consulting allows approaching the concretization of the procedures and rules for organizing communication processes to provide information support at the early stages of entrepreneurial activity.

Key-Words: - network consulting, prospective entrepreneurs, start-up entrepreneurs, cognitive approach, communication model, organization of consulting communication, startup

Received: November 21, 2019. Revised: May 16, 2020. Accepted: May 24, 2020. Published: May 29, 2020.

\section{Introduction}

The early stages of entrepreneurship are a complex iterative process of a person's getting aware of his / her socio-economic interests, forming goals and searching for ways to achieve them through creating his / her own business (Bosman (2013) [2], Ponomarenko \& Gontareva (2017) [17]). The essence of this process is a gradual refinement and transformation of the cognitive model of a business project into an ongoing organizational structure. The driver of the process is the information that a prospective entrepreneur can find, understand and use. Under modern conditions, the main available means of obtaining information is the world network - the Internet. However, the availability of information does not guarantee its quality, i.e., its reliability, relevance, timeliness, intelligibility, sufficiency, consistency, etc. (Gontareva et al. (2018) [10], (2019) [12]). We can agree with the opinion of D. Audretsch and R. Thurik (Audretsch \& Thurik (2004) [1]) that networking intensifies entrepreneurial activity. At the same time, the higher the heterogeneity of the network participants is, the higher the likelihood of the appearance of innovative ideas is. However, transaction costs of finding and verifying information are also higher.

The composition of prospective entrepreneurs is heterogeneous. It is differentiated by the level and orientation of professional training; experience in economic and organizational work; domain of the planned activity; degree of elaboration of the business idea, etc. Effectiveness of the interaction of two heterogeneous media sources and consumers of information can be improved by creating specialized network consulting platforms (NCP) (Bughin et al.
(2010) [3]). The NCP organization model comprises a number of subsystems, in particular: admission rules for network partners; description of key resources and processes; way of forming an interaction workspace; model of consulting communication; description of possible results of the interaction; legal and financial obligations of network partners (Gassman et al. (2017) [7]).

The aim of the article is to form the structure of a model of consulting communication of prospective and novice entrepreneurs based on a network and multilateral platform. The methodological basis of the study is the cognitive approach to the organization of network communication.

The article includes, along with Introduction, Section 2 - Advantages of the network model for organization of consulting support at the early stages of entrepreneurship; Section 3 - Organization of complex communication processes; Section 4 Structure of the model of network consulting communication; Section 5 - Discussion of the proposed model; Section 6 - Conclusion.

\section{Advantages of the network model for organization of consulting support at the early stages of entrepreneurship} Most countries have programs of legal, financial, information and consulting support for entrepreneurship both from the state and charitable organizations. However, the vast majority of startups are provided only basic consultations that involve the formation of skills in the procedures of registration, business planning, accounting, taxation (Malyarets et al. (2017) [15]). However, a business 
plan suggests that the entrepreneur has not only a rather abstract idea of his / her business but also an established business model. A novice entrepreneur has to independently understand the logic of the transition from a generalized mental model to a detailed project and its implementation. On the one hand, this is positive since independent work creates stronger competencies (Gontareva (2015) [11]). On the other hand, the period of knowledge accumulation is lengthening, while many people lack perseverance and motivation to carry out the work of the kind (Gontareva (2011) [9]).

Network consulting at the early stages of entrepreneurship can increase the volume of services provided, expand their composition, and create the prerequisites for more comfortable entry of startups into the market. Based on the woks by A. Gawer and M. Gussumano (Gawer \& Gussumano (2014) [8]), P. Le Masson, A. Hatchuel and B. Weil (Le Masson et al. (2011) [14]), S. Muegge (Muegge (2013) [16]), the main conditions to ensure effectiveness of network consulting include i) availability of open multilateral platforms that specialize in consulting support for novice entrepreneurs; ii) uniting around such platforms communities of participants that can and want to share exclusive knowledge and proven procedures of activities, are able to assess risks for specific business situations, and will help in developing recommendations for solving individual problems; iii) formation of business ecosystems, including both start-up entrepreneurs, who complement each other, and members of the community of consulting platform support.

Fulfillment of the above conditions leads to the emergence of the main and at least two derivative network effects, which accelerate and simplify novice entrepreneurs' getting aware of the algorithm of actions and occurrence of various consequences. The main network effect directly depends on the amount of combinable information in the communication system, consisting of sources, transmission channels and consumers of information. The amount of combinable information characterizes the degree of connectivity of elements in the communication system and is calculated by the Hartley formula:

$$
I_{\text {com }}=N \log _{2} N \text {, }
$$

where $\mathrm{N}$ is the number of elements in the communication system.

If all elements of the communication system are interconnected, we observe the confirmation of Metcalfe's law of network effects, which states that the network utility for the user asymptotically approaches the value of $\mathrm{N}^{2} / 2$. The utility is expressed, in particular, in the fact that the number of elements of the research field and methods for their description are increasing. This simplifies the perception of information for entrepreneurs with different levels of training.

The first derivative network effect depends on the probable amount of information according to Shannon $\left(I_{p r}\right)$ :

$$
I_{p r}=-\sum p_{i}\left(x_{i}\right) \log p_{i}\left(x_{i}\right)
$$

$p_{i}$ is probability of finding by the entrepreneur of the ith exclusive information;

$\mathrm{x}_{\mathrm{i}}$ is possible search result, which depends on the number of elements in the communication system.

The probability that at a random search the required rare information will be found is inversely proportional to the number of information sources. However, in creating the platform, a preliminary specialized selection of sources increases the search efficiency and the likelihood of finding information for specific innovative solutions.

The second derivative network effect is economic in nature. It reflects the fact that the more participants there are in the network, the lower the conditionally fixed costs for each individual communication connection is. With traditional forms of consulting this indicator can increase.

\section{Organization of complex communication processes}

The main goal of a communication interaction of a prospective entrepreneur with network information sources is to provide information on the iterative process of transforming a personified model for obtaining the final result of entrepreneurial activity into an information model (project) of interrelated quantitative descriptions of proportions and relationships, formalized procedures, and rules for performing operations and assessing risk parameters. In terms of information, this is transition from a black-box model with semistructured inputs to a detailed business model which is ready for testing. Cognitively, this is transition from orientation in a problem situation to formation of the conditions necessary for decision-making (Tsvetkov V. Ya. (2014) [18]).

Personification of the initial cognitive model involves the entrepreneur's using implicit knowledge and his / her individual features of perception of reality, which complicates the 
organization of communication interaction among NCP participants. Let us consider three classes of communication interaction between an information consumer and network sources: i) without feedback (linear model); ii) with hard feedback (interactive model); iii) with adaptive feedback (transactional model) (Wood, J. T. (2017) [19]).

Communication without feedback is carried out when the recipient of information independently studies the text of the received message and is not able to directly contact its author for clarification (Hrabovskyi, Y. et al. (2020) [20]). The communication process begins with analyzing the cognitive model of future activities in order to identify its characteristics. For this purpose, it is necessary to find information equivalents to the cognitive image. This will allow highlighting the essential features of the domain and make assumptions about the conditions for implementing the entrepreneurial idea (Popadynets N. et. al. (2017) [21]).

Information equivalent is the initial form of expressing the objective essence of the cognitive model. When searching for an equivalent, one needs to set keywords or other criteria for semantic correspondence. Having received the requested information, the entrepreneur must understand the meaning embedded in them, highlight the elements useful for achieving his / her goals, and introduce them to the initial cognitive model. Understanding the text is possible if the depth and breadth of the entrepreneur's thesaurus in this domain is adequate to the complexity of the material being studied. If such adequacy is absent, it is necessary either to search the network for a less complex text or expand the thesaurus by seeking clarifications of the meaning of terms, definitions, or logic of judgments. At the initial stages of studying the domain, the entrepreneur's knowledge of it is usually fragmented and mosaic; there is no systematic understanding of the essential, necessary and sufficient. Accordingly, it is unlikely to find an effective solution to the problem. To some extent, this situation fits into the understanding of $\mathrm{H}$. Simon's bounded rationality (Gontareva (2011) [11]).

It is possible to increase effectiveness of the information search if there is a database of subject knowledge, language interface, and contextual support system. The entrepreneur describes the problem to be solved and then clarifies it in his / her interaction with the system. In this case, the feedback strictly regulates the communication and reduces it to the selection of descriptions of attributes or objects from the totality contained in the knowledge base. In case of a communication system with a pattern-based interaction, there improved indicators of semantic coordination of a request for information and search results, provided the availability of search field itself. However, the problem of the entrepreneur's orientation in the information received still remains since it requires rethinking and linking it to a specific situation, i.e., carrying out the transition from the semantic essence of information to its pragmatic significance. This serves as a prerequisite for adapting the communication model to subjective conditions of its implementation. Adaptability is achieved in the process of multilateral communication as a way of synthesizing many options that differ in degree of uncertainty and acceptable degree of risk. In the course of discussions, gradual accommodation of opinions and self-identification of the entrepreneur, a scenario of future actions is built. Effective communication is achieved by matching the distribution of positions (roles) of the author, expert, evaluator, mentor, and organizer of the process with regard to the status, competence and experience of the participants in the interaction.

\section{Structure of the model of network consulting communication}

Within the framework of the cognitive approach, there are two main areas of analysis of intelligent systems: i) symbolic, which deals with cognitive logical systems; ii) connectionist, which deals with cognitive neural network systems (Dupoux E. (2016) [6]). In this article, modeling is based on symbolic representation as a more universal one. Semantic, frame and information structures in the form of Frege's triangles are used as modules of the process of consulting communication to solve problems of understanding, substantiating and transforming a business idea (Fig. 1).

An entrepreneur begins the process of objectification of his / her business ideas with subjective ideas about the sphere of commercial activity, its essence, opportunities, and risks. Surveys of prospective entrepreneurs revealed that most of them do not distinguish the concepts of total cost and prime cost of goods or services. Therefore, their judgments about profits are qualitative, not quantitative. To move to the causal relationships between costs and profits, it is necessary to classify costs into fixed and variable, capital and operating ones, etc. At least, an understanding of the entire composition of costs is required. Thus, when calculating equipment costs, transportation, 
construction, installation, commissioning and other types of support costs must be considered.

Interaction with an expert who has a developed network of semantic representations in the form of frames of prototypes can help speed up the process of detailing the classification structure of the domain. To establish the interaction, the entrepreneur and the expert form an understandable to both communication code, which is based on general scientific terms and definitions. As a result of the interaction and use of the knowledge base, the entrepreneur's cognitive model of implicit knowledge is transformed into an intelligent model of externalized knowledge. It is characterized by understanding the essence of the causal structure of the domain, knowledge of the essential relationships between target results and means to achieve them. Assistance in the formation of concepts for choosing specific means of achieving goals under uncertainty is provided by an evaluator of business ideas. To do this, he / she must know and be able to apply methods for assessing economic activity, understand the essence of the differences between operational and strategic efficiency, as well as between other elements of systemic efficiency.

Interaction entrepreneur-evaluator completes the formation of an information model in which the essential relationships of business activities are highlighted and formalized to the level of scalable relations. To proceed with the formation of a business plan, it is necessary to establish interaction with a mentor, who has a semantic network of exoframes, i.e., a set of essential relationships in real-life activities. This complements the entrepreneur's view of dynamic characteristics of relationships between events, conditions, and results. In practice, the roles of an expert, evaluator and mentor can be combined or each role will be performed by a team of specialists.

The organization of communication at NCP is the responsibility of the platform administrator, who forms and monitors the compliance with the rules and procedures for interaction and discussion, and also maintains and updates the platform knowledge base. He must understand the essence of various communicative actions, ensure their acceptance by communicants with regard to situational features, and be ready to resolve conflicts and contradictions.

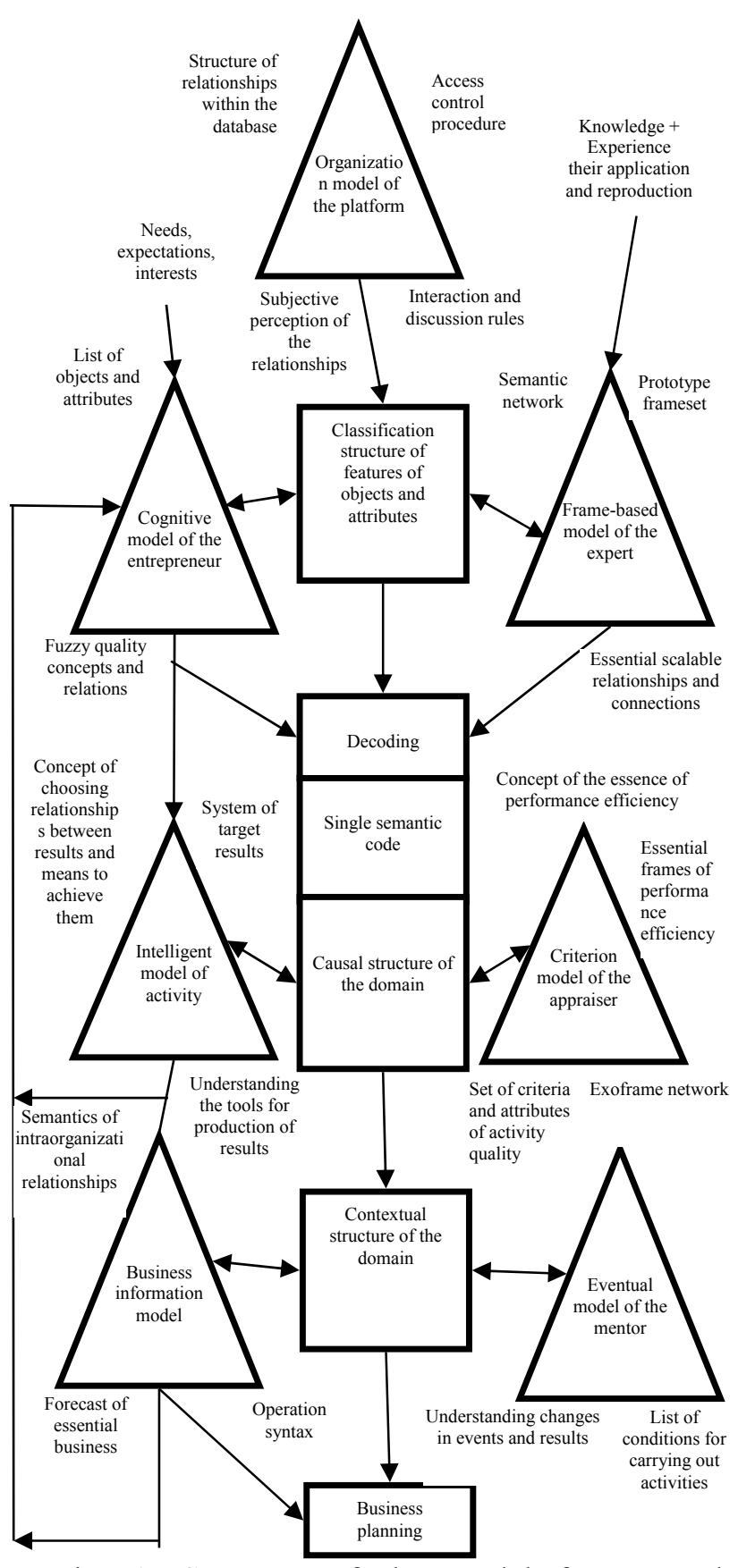

Fig. 1. Structure of the model for network consulting communication [Developed by the author]

\section{Discussion}

Any model focuses only on part of the essential relationships that exist in objective reality. In the model shown in Fig. 1, the presence of various types of semantic noises (DeVito, J. A. (2013) [5]) and methods for their filtration in network consulting communication are essential. At the early stages of entrepreneurial activity, the presence of noises in consulting communication is due to exchanging semantically complex and pragmatically high- 
contextual information, i.e., information the meaning of which depends on the conditions of its use. In this case, the communication process becomes multiple-phase and iterative, with a dynamically changing subject field and the composition of participants. The more complex the semantics of activity is, the more heterogeneous the composition of consultants should be.

The task of communication is rather organizing the process of self-education activities than transferring specific subject knowledge. An entrepreneur independently makes a decision on the composition, volume and complexity of the information consumed. For a better orientation of the entrepreneur, a single semantic code - a conventional structure of terms, concepts and the causal structure of the domain - is formed in the knowledge base. The recommendations of other communicants may not be accepted by the entrepreneur if this does not lead to a violation of the law. However, any actions of the entrepreneur must comply with internal procedures established by the rules of interaction and be justified.

The sequence of forming ideas about entrepreneurial activity is also important. Without orientation in the structure of relationships between results and means of achieving them in a specific domain, without the ability to estimate the number of these relationships and rank them, without a project way of thinking, a business plan will represent a set of poorly connected parts (Daniel (2016) [4], Yastremska \& Strokovich (2015) [22]). Project thinking involves a gradual refinement of the problem with a constant return to the causes and conditions conducive to its emergence. The effectiveness of the process of preparing an entrepreneur for the chosen activity also depends on the degree to which consulting is tied to the logic of real events and facts (Kassean et al. (2015) [13]).

The communication model presented in Fig. 1 basically corresponds to the stated principles and shows the scheme of transition from implicit knowledge to the process of designing a business model. In the future, this will allow proceeding to the formation of rules and procedures for interaction of a novice entrepreneur with carriers of various types of knowledge, based on a network consulting platform.

\section{Conclusion}

Effectiveness of consulting support for start-up entrepreneurs is enhanced due to availability of specialized network platforms that meet the conditions of openness, heterogeneity of their ecosystems and organization of the communication process on the principles of adaptive (transactional) feedback. The result of consulting communication is transformation of the initial business idea, based on personified implicit knowledge of the entrepreneur, into an information-based business model of the startup's activities. The transformation is carried out in the process of dialogues with specialists who play the role of an expert, evaluator, mentor and have proven semantic and pragmatic ideas about the essence of entrepreneurial activity. Organizational functions are performed by the platform administrator, who owns the techniques for conducting complex multilateral communication.

The proposed author's conceptual model of network consulting allows approaching the concretization of the procedures and rules for organizing communication processes to provide information support at the early stages of entrepreneurial activity.

\section{References:}

[1] Audretsch, D \&Thurik, R. (2004) A Model of the Entrepreneurial Economy, Papers on Entrepreneurship, Growth and Public Policy 2004-12, Entrepreneurship, Growth and Public Policy Group, 2004.

[2] Bosman, N. The Global Entrepreneurship Monitor (GEM) and Its Impact on Entrepreneurship Research, Foundations and Trends ${ }^{\circledR}$ in Entrepreneurship, Vol.9, №2, 2013, pp. 143-248. DOI: https://doi.org/10.1561/0300000033

[3] Bughin, J., Chui, M., \& Manyika, J. (2010). Clouds, big data, and smart assets: Ten techenabled business trends to watch, McKinsey Quarterly, 56(1), 2010, pp. 75-86. Retrieved from

de/files/100810/McK_Clouds_big_data_and_s mart assets.pdf

[4] Daniel, A.D. Fostering an entrepreneurial mindset by using a design thinking approach in entrepreneurship education, Industry and Higher Education, Vol.30 Issue 3, 2016, pp. 215-223. DOI: $10.1177 / 0950422216653195$

[5] DeVito, J.A. The Interpersonal Communication Book: 13th Edition, Pearson, 2013.

[6] Dupoux, E. Cognitive Science in the era of Artificial Intelligence: A roadmap for reverseengineering the infant language-learner, Cognition, 173, 2016, pp. 43-59. DOI: 10.1016/j.cognition.2017.11.008

[7] Gassman, O., Framkerberger, K. \& Csik, M. The St. Gallen Business Model Navigator, 
Working Paper University of St.Gallen, 2017. Retrieved from https://www.thegeniusworks.com/wpcontent/uploads/2017/06/St-Gallen-BusinessModel-Innovation-Paper.pdf

[8] Gawer, A. \& Gussumano, M. Industry platforms and ecosystem, Journal of Product Innovation Management, 31(3), 2014, pp. 417433. DOI: $10.1111 /$ jpim.12105. Retrieved from https://core.ac.uk/download/pdf/78063781.pdf

[9] Gontareva, I. V. Influence of timeliness in reproduction processes upon system efficiency of enterprise development, Actual Problems of Economics, 2(116), 2011, pp. 69-76. (Ukr.)

[10] Gontareva, I., Chorna M., Pawliszczy, D., Barna, M., Dorokhov O., Osinska O. Features of the entrepreneurship development in the digital economy, TEM Journal, Vol.7 Issue 4, 2018, Pages 813-822. DOI: 10.18421/TEM74$19 . \quad$ Retrieved from http://www.temjournal.com/content/74/TemJou rnalNovember2018_813_822.pdf

[11] Gontareva, I.V. Syllabus structure in the formation of complex competences, Scientific Bulletin of National Mining University, 1, 2015, pp. 127-132. (Ukr.)

[12] Gontareva, I., Borovyk, M., Babenko, V, Perevozova, I., Mokhnenko, A. Identification of Efficiency Factors for Control over Information and Communication Provision of Sustainable Development in Higher Education Institutions, WSEAS Transactions on Environment and Development, Volume 15, 2019, pp. 593-604. Retrieved from http://www.wseas.org/multimedia/journals/envi ronment/2019/b245115-062.pdf E-ISSN: 22243496

[13] Kassean, H., Vanevenhoven, J., Liguori, E. and Winkel, D. Entrepreneurship education: a need for reflection, real-world experience and action, International Journal of Entrepreneurial Behavior \& Research, Vol.21, No.5, 2015, pp. 690-708. https://doi.org/10.1108/IJEBR-072014-0123

[14] Le Masson, P., Hatchuel, A. \& Weil, B. The Interplay Between Creativity Issues and Design Theories: A New Perspective for Design Management Studies? Creativity and Innovation Management, 20(4), 2011, pp. 217237. DOI: $10.1111 / \mathrm{j} .1467-8691.2011 .00613 . x$

[15] Malyarets, L., Draskovic, M., Babenko, V., Kochuyeva, Z. \& Dorokhov, O. (2017). Theory and practice of controlling at enterprises in international business, Economic annals-XXI, №165, 2017, pp. 90-96.
[16] Muegge, S. Platforms, Communities, and Business Ecosystems: Lessons Learned about Technology Entrepreneurship in an Interconnected World, Technology Innovation Management Review, Vol.3, №2, 2013, pp. 515. Retrieved from https://pdfs.semanticscholar.org/b139/0f5fe27a ebde7bd0df0704e679a5a3981ae2.pdf

[17] Ponomarenko, V. \& Gontareva, I. The system of causal connections between entrepreneurial activity and economic development, Economic Annals-XXI, № 165(5-6), 2017, pp. 4-7. DOI: https://doi.org/10.21003/ea.V165-01

[18] Tsvetkov, V.Ya. Cognitive Information Models, Life Science Journal, Vol.11, №4, 2014, pp. 468-471.

[19] Wood, J. T. Communication in Our Lives: 8th Edition. Cengage Learning, 2017.

[20] Hrabovskyi, Y., Babenko, V., Al'boschiy, O., Gerasimenko, V. (2020). Development of a Technology for Automation of Work with Sources of Information on the Internet. WSEAS Transactions on Business and Economics, Vol. 17, Art. \#25, pp. 231-240. doi: 10.37394/23207.2020.17.25

[21] Popadynets N., Shults S., Barna M. (2017). Diferences in consumer buying behaviour in consumer markets of the EU member states and Ukraine. Economic Annals-XXI, 166(1-2), pp. 26-30. doi: https://doi.org/10.21003/ea.V16605

[22] Yastremska O.M. \& Strokovich G.V. Methodical approach to strategic planning of quality of functioning of enterprise, Actual problems of economy, № 4, 2015, pp. 46-53. (Ukr.) 